\title{
Reducionismo versus complexidade: O pensamento de Phil Anderson e sua influência em outras áreas
}

\author{
Reductionism vs complexity: Philip Anderson's thoughts and their influence on other fields of knowledge
}

\author{
Peter A. Schulz ${ }^{* 10}$ \\ ${ }^{1}$ Universidade Estadual de Campinas, Faculdade de Ciências Aplicadas, CEP 13484-350, Limeira, SP, Brasil.
}

Recebido em 07 de outubro de 2020. Aceito em 19 de outubro de 2020.

\begin{abstract}
Nesse artigo é discutido o artigo de Philip Anderson "More is different" e sua importância para o estabelecimento da complexidade como um tema em oposição ao reducionismo, bem como de sua hierarquia das ciências. A partir de um caso simples na Física, a apropriação do tema da complexidade em outras ciências é ilustrada pelos artigos mais recentes na literatura acadêmica.
\end{abstract}

Palavras-chave: complexidade, reducionismo, emergência, interdisciplinaridade.

In this work, the relevance of the article by Philip Warren Anderson, "More is different", for establishing complexety as a thematic category opposed to reductionism, is discussed, as well as his hierarchy of sciences. From a simple case in Physics, the appropriation of complexity in other sciences is illustrated by recente articles in the academic literature.

Keywords: complexity, reductionism, emergence, interdisciplinarity.

\section{Introdução: A construção de um Grande Tema da Física}

A atividade cotidiana de pesquisa é, na maioria das vezes, muito imediatista e esquecemos constantemente a História, a mais importante das ciências, segundo César Lattes. De fato, quando lemos os artigos científicos da área, percebemos poucas referências que não sejam recentes. No entanto, é justamente a História e a Filosofia que trazem luz sobre as motivações, os temas e a imaginação científica que orientam os físicos no seu trabalho diário. Gerald Holton, físico e historiador, debruça-se sobre exatamente esses aspectos em seu livro A imaginação científica [1], que propõe a análise temática.

"Em muitos conceitos, métodos e proposições ou hipóteses da ciência, passados e presentes, há elementos que funcionam como temas, forçando ou motivando e, por vezes, guiando (normalizando) ou polarizando a comunidade científica. Nas próprias apresentações publicadas que o cientista faz de seu trabalho, e durante qualquer discussão científica que se siga, esses elementos não estão, em geral, explicitamente em causa." (Holton, A imaginação científica, p. 21)

\footnotetext{
*Endereço de correspondência: peter.schulz@fca.unicamp.br
}

Os temas são poucos e não há necessariamente um fundamento epistemológico para eles, embora nos guiem na maneira de fazer ciência. Afinal, nas palavras de Ronaldo Marin e Gustavo Rick Amaral, o processo de fazer ciência é "trocar a roda com o carro em movimento" 2] e os temas foram surgindo. Um dos primeiros, e mais importantes, que na ciência moderna remonta aos seus primórdios, é o reducionismo: encontrar leis simples (poucas) que descrevam duas ou mais classes de fenômenos conhecidos. A mecânica de Isaac Newton é o primeiro grande exemplo, pois sua gravitação universal descreve os movimentos mundanos perto da superfície terrestre e os das então chamadas esferas celestes. O eletromagnetismo de James Clerk Maxwell, dois séculos depois, é outro grande exemplo, fenômenos magnéticos e elétricos são unificados em apenas quatro equações de Maxwell, levando a um resultado surpreendente: a natureza eletromagnética da luz. É o mesmo tema que motivou as "teorias unificadas", na busca de uma teoria única para juntar as forças eletromagnéticas com as nucleares, fortes e fracas, e a gravitação. Esse tema, a síntese, ou unificação, ou reducionismo é declarado por Steven Weinberg em seu artigo na Scientific American em 1974 [3: "uma das esperanças duradouras do homem tem sido a de encontrar leis gerais mais simples". Weinberg é um dos contribuidores fundamentais na construção do Modelo Padrão para as partículas elementares, que as descreve colocando em um mesmo arcabouço três das quatro forças, a gravitação ficou de fora. Mais recentemente, o 
tema reducionismo na Física foi rebatizado como "teoria do todo", sendo Stephen Hawking, seu mais emblemático proponente.

Essas manifestações acima do mesmo tema, reducionismo, são as frentes que ficaram notórias, mas em todas as subáreas elas se manifestam, como quando buscada e hoje aplicada uma descrição geral do que são metais, semicondutores ou isolantes com a mesma teoria. Mas há uma sutileza nisso. Quando um cientista de materiais identifica um novo material, ele será condutor ou isolante, não há uma motivação por parte do pesquisador para que seja uma coisa ou outra. No "grande reducionismo", por outro lado, não há uma necessidade experimental ou lógica para uma teoria que abarque a Mecânica Quântica e a Relatividade Geral, apenas a "esperança duradoura do homem" para que assim seja, o que pode ser chamado de compromisso temático.

\section{Reducionismo Chega ao Seu Limite e Surge um Novo Tema: A Complexidade}

O reducionismo como tema, junto com a tradição de que qualquer evidência de algo errático ou de incerteza na natureza seria explicável por uma teoria mais sutil, que restabelecesse a ordem, enfrentaram com sucesso um primeiro desafio surgido ainda no século XIX. Esse desafio era o movimento Browniano [4], identificado pelo padre botânico, cujo nome batiza o fenômeno, em 1828 . A ordem, por trás do movimento errático das pequenas partículas em suspensão em um líquido, pode ser descrita por equações simples, construídas em última instância sobre as leis simples de movimento da mecânica clássica. Albert Einstein foi o responsável, com seu famoso artigo sobre o movimento Browniano de 1905, por essa reafirmação do reducionismo. Por outro lado, Einstein foi responsável também pelo primeiro beco sem saída para o mesmo reducionismo com a sua busca pela Teoria unificada para a gravitação e o eletromagnetismo. O tema se manteve, envolvendo pontos de partida diferentes, como o já citado modelo padrão (que unificou o eletromagnetismo com outras forças, mas não a gravitacional), um sucesso parcial, e para a Teoria do todo estamos longe de anunciar uma vencedora.

Stephen Hawking, entusiasmado inicialmente com a possibilidade do reducionismo final, partindo de seus estudos de buracos negros (onde a Relatividade Geral e a Mecânica Quântica precisariam entrar em acordo), chegou a deduzir uma equação onde pela primeira vez a constante universal da gravitação, G, e a constante de Planck, h, se encontravam na equação que define $\mathrm{S}$, a chamada entropia de Bekenstein-Hawking, na qual k é a constante de Boltzmann, A a área do buraco negro e c a velocidade da luz:

$$
S=\frac{\pi A k c^{3}}{2 h G}
$$

Essa equação aparece em um artigo de 1975 [5]. Com Hawking, o reducionismo abraça novamente o "Fim da Física", que em outro contexto já havia sido anunciado no final do século XIX, quando, para muitos, não haveria mais nada a ser descoberto [6]. O eminente físico britânico declara no artigo "O fim da Física teórica está próximo?" [7] de 1981:

\begin{abstract}
"Neste artigo eu quero discutir a possibilidade de que o objetivo da física teórica pode ser alcançado em um futuro não tão distante, digamos, até o final do século. Com isso eu quero dizer que poderíamos ter uma teoria completa, consistente e unificada das interações físicas que descreveriam todas as possíveis observações."
\end{abstract}

No entanto, já no presente século, Hawking abandona a possibilidade desse tema, declarando que "físicos têm buscado há tempos uma teoria final que unificaria toda a Física. Em vez disso, eles talvez precisem se ajustar a várias" 8, 17 Ao mesmo tempo, uma candidata à teoria do todo, a "teoria das cordas", começava a passar por novos impasses. Essa teoria ainda é um arcabouço matemático, para a qual, após 40 anos de ausência de evidências empíricas, seus defensores chegam a puxar as cordas para propor que tais evidências não deveriam mais ser critério para a aceitação de uma teoria [9]. A questão, ainda em aberto, convive também nesses 40 anos com o bem mais promissor, e em expansão, antitema do reducionismo: a complexidade.

\section{O anti-tema de Phil Anderson: O Todo Não é Tudo}

Pouco tempo antes da pista que Hawking encontrou nos buracos negros para conectar a Gravitação e a Mecânica Quântica, equação (1), um ensaio é publicado no sentido oposto. Na revista Science, em 1972, aparece o artigo "More is different" [10], do já renomado físico Philip Warren Anderson, um artigo que não é técnico e que virou um manifesto, marco da complexidade como tema absolutamente necessário para as ciências. São quatro páginas incompletas, sendo a primeira, não inteiramente voltada à Física, uma das mais influentes sobre outras áreas do conhecimento já escrita por um físico.

$\mathrm{O}$ artigo, que tem como subtítulo a frase "quebra de simetria e a estrutura hierárquica das ciências", abre com uma menção ao reducionismo, afirmando que "a hipótese reducionista pode ainda ser um tópico de controvérsia entre filósofos, mas entre a grande maioria dos cientistas ativos eu penso que é aceita sem questionamento". No entanto, logo em seguida, afirma que se opor a esse ponto de vista é o principal propósito de

\footnotetext{
${ }^{1}$ A ideia do fim da Física ainda seria propalada no final do século passado através do livro "The end of Science" de John Horgan de 1996.
} 
seu artigo. Antes de colocar esse seu ponto de vista, é importante observar que um cientista político, Don K. Price, em outro ensaio publicado na Science alguns anos antes - "Purists and politicians" [1] -, argumentava que a hipótese reducionista era uma das origens da revolta contra a ciência, que se verificava na época. Em um contexto de guerras, a Fria e a do Vietnã, a "revolta" contra as ciências naturais seria engendrada por expoentes das ciências humanas, como Herbert Marcuse. Resumidamente, a atitude reducionista, que levava a tomadas de decisão somente baseadas na ciência, não levaria em conta a complexidade dos fatos sociais. O manifesto de Anderson acabou sendo também uma resposta a essa dicotomia entre ciências naturais e humanas.

Anderson, antes de expor o argumento em favor da necessidade da complexidade, faz uma alusão a outro anúncio de um "fim da Física", no âmbito, não das teorias unificadas como previsto por Stephen Hawking, ou por alguns físicos na virada do século XX, mas nas ciências dos materiais. "Um líder na área de ciências dos materiais incitou os participantes em um encontro dedicado a 'problemas fundamentais em Física da Matéria Condensada' a aceitar que restaram poucos, ou talvez nenhum, problemas desse tipo e que o que restava eram meras aplicações". O próximo parágrafo de Anderson expõe a principal falácia desse ponto de vista: "a habilidade de reduzir tudo a leis fundamentais simples não implica na habilidade de, a partir dessas leis, reconstruir o universo". Ele ilustra seu postulado usando as partículas elementares, cujo modelo padrão - então em desenvolvimento - era um estandarte do reducionismo, como ponto de partida:

"O comportamento de grandes e complexos agregados de partículas elementares, como se vê, não pode ser entendido em termos de uma simples extrapolação das propriedades de umas poucas partículas. Em vez disso, a cada nível de complexidade propriedades inteiramente novas surgem, cujo entendimento requer pesquisa tão fundamental em sua natureza, quanto qualquer outra" (Anderson, "More is different").

\section{Um pequeno Exemplo de Complexidade}

O trecho acima foi revisitado com exemplos no âmbito da Física por Robert Laughlin e David Pines em um outro manifesto, que sintetiza o postulado de Anderson com um jogo de palavras: "the theory of everything is not even remotely a theory of every thing" [12]. Apesar dessa coleção de exemplos em que agregados complexos de partículas não são simples extrapolações de propriedades de poucas partículas, vale a pena incluir mais um, próximo ao cotidiano de todos, que já enfrentaram congestionamentos de trânsito sem causa aparente. Uma
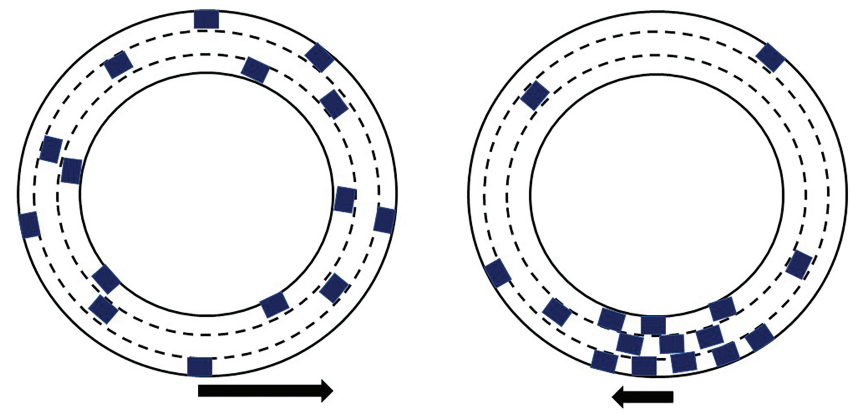

Figura 1: No painel da esquerda estão representados os movimentos uniformes circulares dos carros em sentido anti-horário. No painel da direita, uma "onda de densidade de tráfego", deslocando-se em sentido horário. As setas indicam a velocidade de um dos carros no painel da esquerda e do congestionamento no da direita.

simulação numérica de tráfego de uma das situações mais simples, um circuito circular, ilustra claramente isso. A simulação é do grupo de Matias Treiber da Universidade Técnica de Dresden [13] e a Figura 1] é uma ilustração do fenômeno. No painel da esquerda temos os movimentos circulares uniformes de um conjunto de automóveis, descritos pela Mecânica Clássica e presentes em todos os livros textos de Física. No entanto, se incluirmos as ultrapassagens, com maior ou menor segurança, para um tráfego mais ou menos denso, chegamos à situação do painel da direita. Emerge uma "onda de densidade de tráfego", que se desloca no sentido contrário do movimento dos carros, complexidade que não pode ser inferida dos movimentos circulares uniformes dos carros individualmente.

Um novo nível de complexidade, aliás, acontece também com a descrição do movimento Browniano, ao contrário do que diziam os reducionistas: do movimento independente de cada molécula de água, colidindo com as partículas de pólen, observadas pela primeira vez por Robert Brown, não é possível inferir como é o errático deslocamento dessas partículas em suspensão, descrito por Albert Einstein em sua teoria.

\section{A hierarquia das Ciências de Anderson e Sua Influência}

Anderson completa a primeira página do seu manifesto propondo uma extrapolação de sua visão antireducionista. Com todo o cuidado de dizer que é uma opinião, sugere uma "hierarquia de ciências":

"As entidades elementares da ciência X obedecem às leis da ciência Y. No entanto, essa hierarquia não implica que a ciência $\mathrm{X}$ seja apenas 'aplicação de Y'. A cada estágio são necessários leis, conceitos e generalizações inteiramente novas [...]. Psicologia não é Biologia aplicada, nem Biologia é Química aplicada." 
A ideia nesse curto e simples parágrafo foi retomada exaustivamente por filósofos da ciência ${ }^{2}$ e, além disso, apresenta um outro sub manifesto: as ciências humanas são reconhecidas como ciências e estão no topo da escala hierárquica de complexidade. Seu quadro termina com as Ciências Sociais não sendo meramente Psicologia aplicada em analogia às ondas de densidade de tráfego, que não são simplesmente um conjunto de movimentos circulares uniformes.

A influência de seu manifesto pela complexidade pode ser pensada a partir de uma representação utilizada frequentemente, o número de citações. Pela plataforma Web of Science são aproximadamente 1300 citações até setembro de 2020 e, além de Física, são listados artigos de História e Filosofia da Ciência, Biologia e Neurociências. A influência, no entanto, é mais ampla em muitos outros documentos acadêmicos não indexados, com as mais de 4200 citações pelo Google acadêmico. Essa influência ainda não diminuiu significativamente com o tempo e alguns artigos publicados em 2020 dão uma amostra disso, bem como a amplitude da apropriação dessas ideias publicadas em 1972.

$\mathrm{O}$ artigo multidisciplinar "relacionando tamanho e funcionalidade de redes sociais humanas através da complexidade" [14] cita o manifesto de Anderson "em relação à desconexão entre microdinâmica e a macrodinâmica emergente em sistemas complexos, que passam por transições de fase". Shimon Maron [15] escreve um ensaio discutindo uma possível incompatibilidade entre Psicologia e Neurofisiologia, mencionando Anderson para pontuar a necessidade de pontes epistemológicas entre os diferentes níveis hierárquicos.

O artigo "Dinâmica de coordenação: um fundamento para entender o comportamento humano" [16], cita Anderson, bem como Laughlin e Pines, na retomada da discussão entre reducionismo e complexidade para o fundamento proposto ali. Talvez o mais curioso exemplo seja o uso da ideia de emergência proposta por Anderson em um trabalho sobre "uma ontologia crítica de processos de transformação econômica: contribuições de Marx" [17].

Esses exemplos de apropriação das ideias de Anderson em torno da complexidade não devem ser tomados de forma anedótica, como, por exemplo, no uso de analogias insustentáveis para justificação de pseudociências. Dessas analogias é vítima Albert Einstein, com os inúmeros artigos(?) sobre paranormalidade em que o paradoxo EPR seria demonstração(?) de telepatia 18. No caso em que "mais é diferente" temos uma proposta de um tema na concepção de Gerald Holton [1], mas agora não só no interior de apenas uma ciência, mas para articulações interdisciplinares. Um tema tão legítimo quanto o que motiva a busca da "Teoria do todo".

\section{Agradecimentos}

O autor agradece a Eduardo Miranda por chamar a atenção a esse artigo de Phil Anderson no final do século passado.

\section{Referências}

[1] G. Holton, A imaginação científica (Editora Zahar, Rio de Janeiro, 1979).

[2] R. Marin e G.R. Amaral, Os avanços da ciência podem acabar com a filosofia? (Estação das Letras, Barueri, 2020).

[3] S. Weinberg, Scientific American 231, 50 (1974).

[4] S.R.A. Salinas, Revista Brasileira de Ensino de Física 27, 263 (2005).

[5] S.W. Hawking, Communication Mathematical Physics, 43, 199 (1975)

[6] P.A. Schulz, Revista Brasileria de Ensino de Física 29, 509 (2007).

[7] S.W. Hawking, Phys. Bull. 32, 15 (1981).

[8] S.W. Hawking e L. Mlodinow, Scientific American 303, 69 (2010).

[9] N. Wolchover, A Fight for the Soul of Science, disponível em: https://www.quantamagazine.org/physicists-and-p hilosophers-debate-the-boundaries-of-science-20151216, acessado em 30/9/2020

[10] P.W. Anderson, Science 177, 393 (1972).

[11] D.K. Price, Science 163, 25 (1969).

[12] R.B. Laughlin e D. Pines, PNAS 97, 28 (2000).

[13] https://traffic-simulation.de/ring.html

[14] B.J. West, G.F. Massan, G. Culbreth, R. Failla, M. Bologna, R.I.M. Dunbar e P. Grigolini, PNAS 117, 18355 (2020)

[15] S. Maron, Neuron 107, 600 (2020).

[16] E. Tognoli, M. Zhang, A. Fuchs, C. Beetle e J.A Scott Kelso, Frontiers in Human Neuroscience 14, 317 (2020).

[17] G. Bonifati, Cambridge Journal of Economics 44, 1031 (2020).

[18] P.A. Schulz, A sinuca de Einstei, disponível em: https://www.unicamp.br/unicamp/ju/artigos/peter-sc hulz/sinuca-de-einstein, acessado em 30/9/2020. 